\title{
STATURE ESTIMATION FROM THE ANTHROPOMETRIC MEASUREMENTS OF FOOT OUTLINE IN ADULT INDIGENOUS MELANAU ETHNICS OF EAST MALAYSIA BY REGRESSION ANALYSIS
}

\author{
Hairunnisa Bt Mohd Anas Khan ${ }^{1}$ and T. Nataraja Moorthy ${ }^{2}$ \\ ${ }^{1}$ Forensic Division, Chemistry Department of Malaysia, Bintulu, Sarawak State, East Malaysia. \\ ${ }^{2}$ School of Health Sciences, Universiti Sains Malaysia, Health Campus Kubang Kerian, \\ Kelantan State, Malaysia.
}

\begin{abstract}
A person's stature is an identifying characteristic in forensic investigation. Footprint is the one of the valuable physical evidence encountered in the crime scenes. Analysis of footprints helps in estimation of an individual's stature because of the existence of strong correlation between foot impression and height. Foot impressions are still found at crime scenes, since offenders often tend to remove their footwear either to avoid noise or to gain better grip in climbing walls, etc., while entering or exiting. In Asian countries like India, Malaysia, Sri Lanka, Thailand, Indonesia, there are people who still have the habit of walking barefoot. The footprint provides the size dimensions of the foot's plantar surface actually touching the floor or hard surface, which produces a twodimensional footprint while foot outline provides the size parameters of the fleshed bare foot and also represents the boundaries of the foot's impression in soft soil, mud, or any other substances that produces a three-dimensional footprint impression. The review of literature revealed that very limited studies were conducted on stature estimation from foot outline measurements. Most of the foot/foot impression studies have been conducted on mixed population. The researchers cautioned that racial and cultural aspects of foot morphology must be considered while conducting the foot impression study. In stature estimation using foot impression, formulae derived for a particular population is erroneous to apply for other populations. Hence the present study aims to derive population specific equations to estimate stature from foot outlines
\end{abstract}

of indigenous Melanau ethnics of East Malaysia.

\section{INTRODUCTION}

An aspect of human identification that has received scant attention from forensic anthropologists is the study of human feet and the footprints made by the feet ${ }^{1}$. There is also a relationship between each part of the body and the whole body. Nothing exemplifies this truth more than the relationship that various parts of the body have to the stature of an individual ${ }^{2}$. In this manner, an individual's footprint may represent his or her identity. The characteristic features in foot impression can provide useful clues to establish identity whenever complete or partial two dimensional (2D) and three dimensional (3D) foot impressions are recovered at the crime scenes ${ }^{3}$. In Asian countries like India, Malaysia, Sri Lanka, Thailand, Indonesia, there are people who still have the habit of walking barefoot. Foot impressions are still found at crime scenes, since offenders often tend to remove their footwear either to avoid noise or to gain better grip in climbing walls, etc., while entering or exiting ${ }^{4}$. Analysis of foot ${ }^{5-11}$ and footprints ${ }^{12-}$ 18 help in estimation of an individual's stature because of the existence of a strong correlation between one's stature and foot/footprint/foot outline length. The footprint provides the size dimensions of the foot's plantar surface actually touching the floor or hard surface, which produces a two-dimensional (2D) footprint impression. On the other hand the foot outline provides the size parameters of the fleshed bare foot and also represents the boundaries of the foot's impression in soft soil, mud, or any other substances that produces a three-dimensional 
(3D) footprint impression ${ }^{12}$. The review of literature revealed that very limited studies were conducted on stature estimation from foot outline measurements ${ }^{19-22}$. Most of the foot/foot print studies have been conducted on mixed population. The researchers cautioned that racial and cultural aspects of foot morphology must be considered while conducting the foot print study ${ }^{20}$. The people from different regions and races in a country bear different morphological features and hence a single formula cannot represent for all races or regions in a country ${ }^{\mathbf{4 - 2 0}}$. The researchers have concluded that toes-to-heel footprint/foot outline length in a foot impression has more reliability of prediction than from any other measurements, such as breadth at ball/heel and big toe breadth/length ${ }^{\mathbf{1 7 - 2 2}}$. Hence, the present study attempts the stature estimation from all toes-to-heel lengths in a foot outline and to derive population specific regression equations suitable for Melanau ethnics, an endogamous group in Borneo Island, East Malaysia.

\section{MATERIALS AND METHODS Research location}

The study was carried out at Sarawak state, East Malaysia. Sarawak state is home to 28 ethnic groups, each with their own distinct language, culture and lifestyle. The subjects were from colleges, universities and general public. The Melanaus are a people who live on the island of Borneo, primarily in Sarawak, east Malaysia. They are among the earliest settlers of Sarawak, and speak a Northwest Malayo-Polynesian language. They are mostly farmers, fishermen, and reputed as some of the finest boat-builders and craftsmen.

Figure-1 depicts the sampling area in East Malaysia located in Borneo Island. Before started the research, concurrence was obtained from Sarawak Chief Minister vide No. JKM.P/DEV/16/005 /12(44), for sample collection. Informed consent was also obtained from all participants and followed the procedure in accordance with the ethical standards of Universiti Sains Malaysia Human Research Ethic Committee \{Ethical approval No. USMKK/ PPP/ JEMPeM [247.4.(2.12] / Amend (01) dated 8th April 2012 of USM\}.

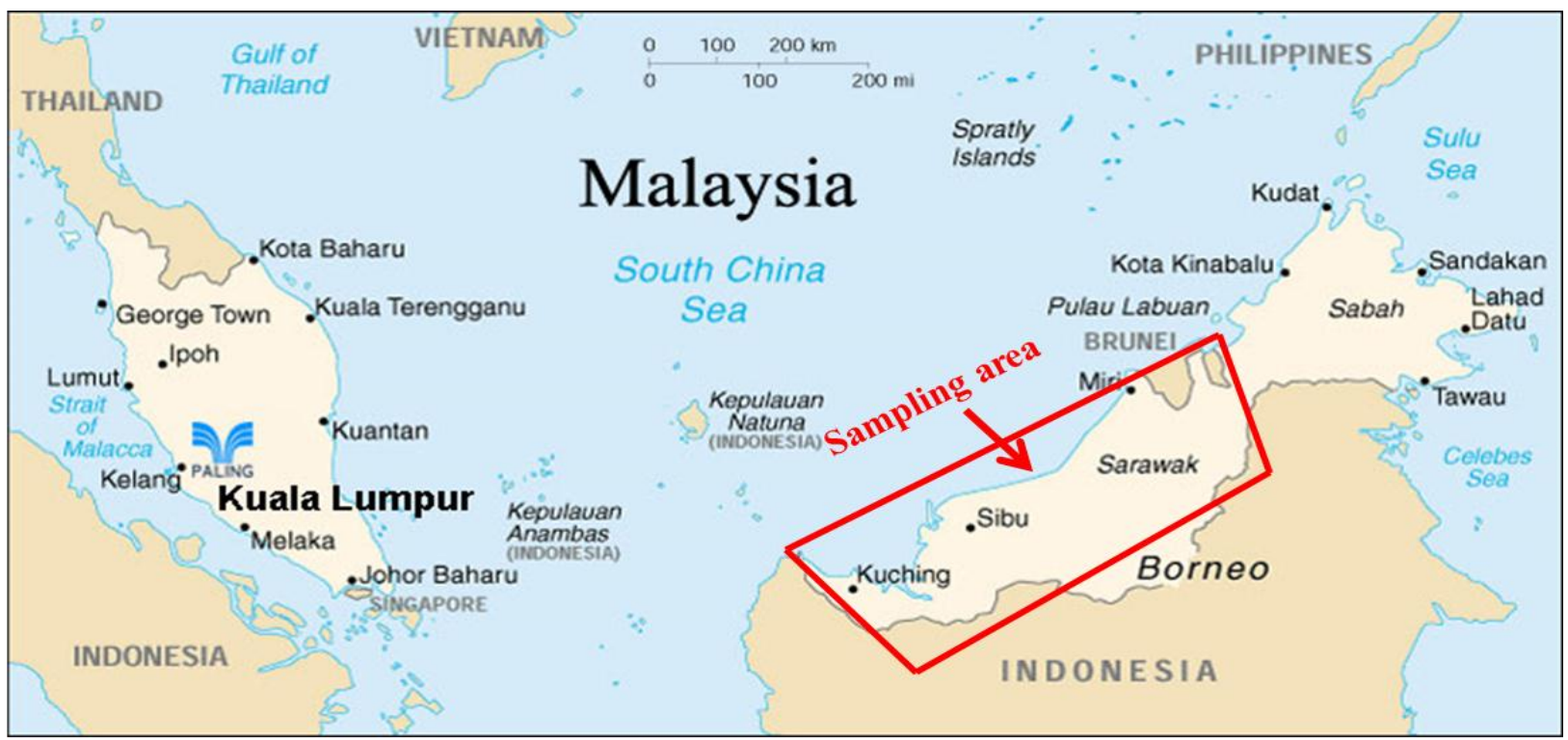

Source: www.malaysiamap.org/map-search-detaillc0f.html

Figure 1: Map of Malaysia showing the sampling area, Sarawak state of east Malaysia in Borneo Island 


\section{Sample collection}

\section{Recording of stature}

The study involved 210 adult Melanaus (105 males, 105 females) of age ranged from 18 to 59 years. Subjects with any apparent foot-related disease, pregnancy, orthopedic deformity, physical impairment, injury, disorders and age below 18 years were excluded from the study. Stature of each subject was measured using a portable body meter measuring device (SECA model 206) following the standard procedure ${ }^{20}$ 22. Considering the diurnal variation in stature, the height of the subjects was measured approximately at a fixed time in the evening. The diurnal change in height of a person was reported and confirmed by the researchers ${ }^{23-24}$. The stature of each subject was measured following Krishan ${ }^{20}$ and Nataraja Moorthy ${ }^{21}$ as follows. Stature was measured without head and footwear using a portable body meter measuring device. The body meter was suspended upright against the wall and measurements were taken to the nearest $0.5 \mathrm{~cm}$. The subject was advised to stand under the body meter with his heels together and weight evenly distributed between both feet. Stature was measured in $\mathrm{cm}$ as the vertical distance between the vertex and the sole of the foot when the individual was standing barefoot with head held in the Frankfurt horizontal plane with eyes looking forward. The measurements were repeated until concordant values were achieved.

\section{Recording of foot outline and diagonal length measurements}

Just prior to research participation, the subjects were advised to wash their feet with soap and water. Then the subject was requested to place the left foot on an A4 size white paper and the foot outline was drawn with a sharp-pointed pencil. The pencil was held perpendicular to the paper as it traced around the margin of the foot. With the foot still on the paper, the anatomical landmarks of the foot, namely mid-rear heel point (pternion, OP) in the base line BL and most anterior points of all toes (LT1-LT5) were marked. The procedure was repeated for the right foot and for the other subjects. Following Krishan $^{20}$ and Nataraja Moorthy ${ }^{21}$, the designated longitudinal axis (DLA) and base line (BL) were drawn on the foot outlines. Then five diagonal foot outline lengths were taken from the mid-rear heel point (OP) to most anterior point of each left toe (LT1, LT2, LT3, LT4, and LT5). The left foot outline length measurements were designated as OPLT1, OPLT2, OPLT3, OPLT4, and OPLT5. The procedure was repeated for the right foot and the right foot outline lengths were designated as OPRT1, OPRT2, OPRT3, OPRT4, and OPRT5. Figure- 2 shows the land marks and length measurements in a right foot outline. All foot outlines and information relating to participants were coded with sample ID for anonymity.

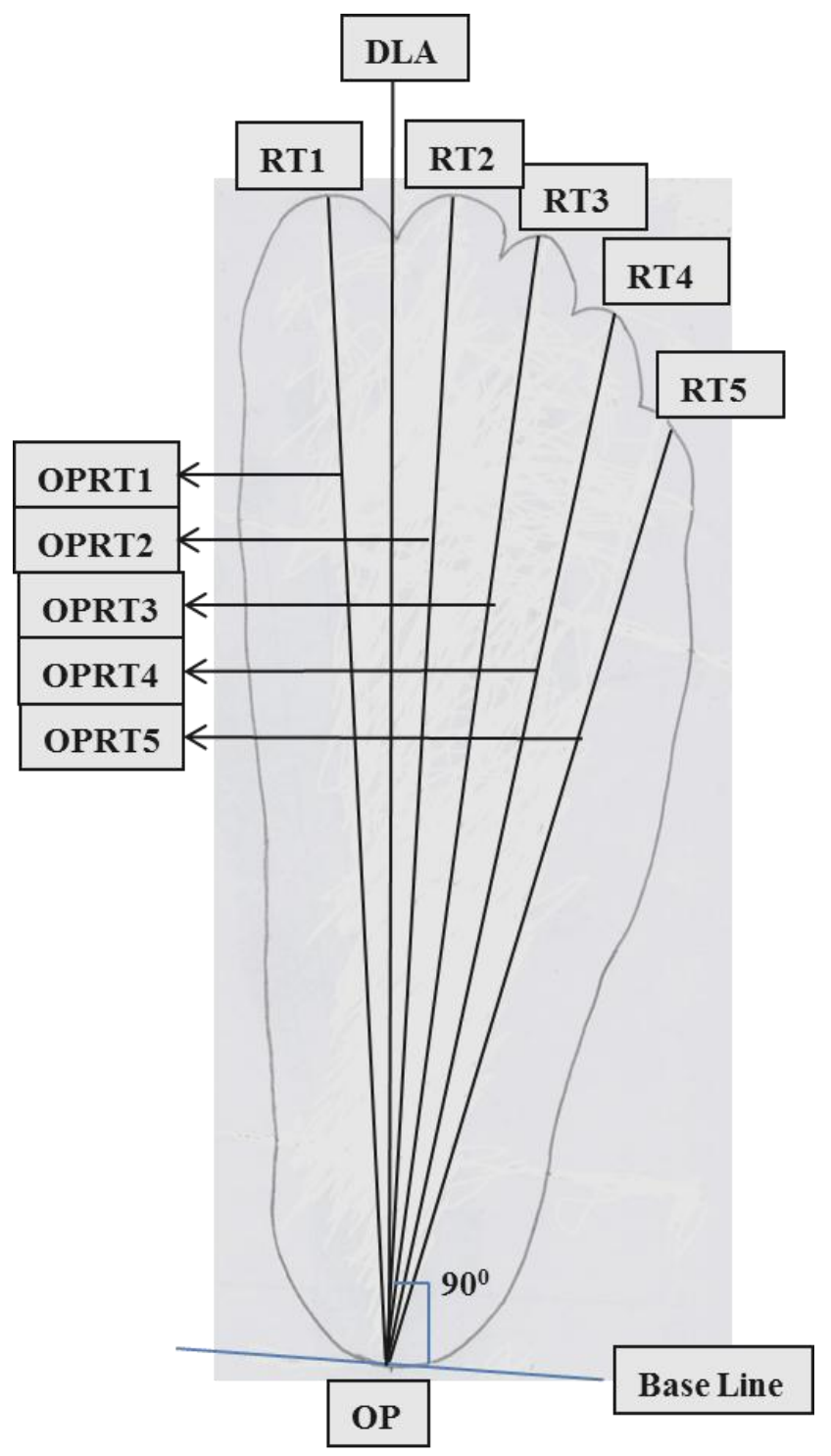

Figure 2: Landmarks and diagonal length measurements on right foot outline 


\section{Statistical analysis}

The data were analyzed using PASW Statistics version 20 (Predictive Analytic Software). Bilateral asymmetry was calculated for each of the foot outline measurements and tested for significance using one sample t-test. Pearson's correlation coefficients (R) between various feet outline lengths and stature were obtained. The linear regression analysis method was employed to derive regression equations for stature estimation from various foot outline lengths since stature estimation from foot outline length is more accurate and reliable with regression analysis ${ }^{25}$.

\section{RESULTS}

All footprint and foot outline measurements exhibit statistically positive significant correlation with stature. Table-1 shows the descriptive statistics of stature measurements in males, females and pooled sample. In males, the stature ranges from 153.5 to $187.5 \mathrm{~cm}$ (mean $165.7 \mathrm{~cm}$ ) and in females, it ranges from 137.0 to $170.2 \mathrm{~cm}$ (mean $153.3 \mathrm{~cm}$ ). In pooled sample, the stature ranges from 137.0 to $187.5 \mathrm{~cm}$. The results showed that mean stature is found to be significantly higher in males than females.

Table 1: Descriptive statistics of stature in males, females and pooled sample of adult Melanau ethnics in East Malaysia.

\begin{tabular}{|c|c|c|c|c|c|c|c|c|c|c|c|c|c|c|c|}
\hline \multirow{2}{*}{$\frac{\frac{0}{0}}{\frac{\pi}{\pi}}$} & \multicolumn{5}{|c|}{ Male $(\mathrm{N}=105)$} & \multicolumn{5}{|c|}{ Female $(\mathrm{N}=105)$} & \multicolumn{5}{|c|}{ Pooled sample $(\mathrm{N}=210)$} \\
\hline & $\Xi$ & $\sum^{\stackrel{x}{ \pm}}$ & حิ & $\stackrel{\varpi \Xi}{\Sigma}$ & 㝏 & $\Xi$ & 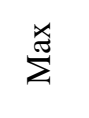 & حิ & $\stackrel{\varpi}{\varpi}^{\Xi}$ & ถิ & 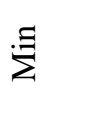 & 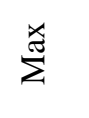 & $\widehat{\approx}$ & 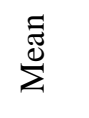 & ڤิ \\
\hline 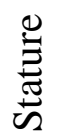 & 153.5 & 187.5 & 34.0 & 165.7 & 5.7 & 137.0 & 170.2 & 33.2 & 153.3 & 5.9 & 137.0 & 187.5 & 50.5 & 159.5 & 8.5 \\
\hline
\end{tabular}

SD: standard deviation; RD: range difference; Min: minimum; Max: maximum;

Table-2 depicts descriptive statistics of foot outline lengths in males, females and pooled sample. The mean foot outline length measurements in males $(21.3-25.3 \mathrm{~cm})$ are found to be significantly higher than females (19.2-21.1) showing the existence of gender difference. First toe-heel length (OPRT1 and OPLT1) measurement is found to be the longest in both males and females on right and left sides.

Table 2: Descriptive statistics of foot outline length (in centimetres) measurements in males, females and pooled sample of adult Melanau ethnics in East Malaysia.

\begin{tabular}{|c|c|c|c|c|c|c|c|c|c|c|c|c|c|c|c|c|c|c|}
\hline \multirow[t]{2}{*}{ Variables } & \multicolumn{6}{|c|}{ Male $(\mathrm{N}=105)$} & \multicolumn{6}{|c|}{ Female (N=105) } & \multicolumn{6}{|c|}{ Pooled sample $(\mathrm{N}=210)$} \\
\hline & $\mathrm{N}$ & $\mathrm{RD}$ & Min & $\operatorname{Max}$ & Mean & SD & $\mathrm{N}$ & $\mathrm{RD}$ & Min & Max & Mean & SD & $\mathrm{N}$ & RD & Min & Max & Mean & SD \\
\hline OPLT1 & 105 & 7.0 & 22.9 & 29.9 & 25.3 & 1.1 & 105 & 5.5 & 20.5 & 26.0 & 23.0 & 1.0 & 210 & 9.4 & 20.5 & 29.9 & 24.1 & 1.6 \\
\hline OPLT2 & 105 & 7.7 & 22.8 & 30.5 & 25.2 & 1.1 & 105 & 6.0 & 19.7 & 25.7 & 22.7 & 1.1 & 210 & 10.8 & 19.7 & 30.5 & 24.0 & 1.7 \\
\hline OPLT3 & 105 & 7.6 & 22.1 & 29.7 & 24.4 & 1.1 & 105 & 5.9 & 18.9 & 24.8 & 23.0 & 1.1 & 210 & 10.8 & 18.9 & 29.7 & 23.2 & 1.6 \\
\hline OPLT4 & 105 & 7.3 & 20.8 & 28.1 & 23.1 & 1.0 & 105 & 5.2 & 18.3 & 23.5 & 20.8 & 1.0 & 210 & 9.8 & 18.3 & 28.1 & 22.0 & 1.5 \\
\hline OPLT5 & 105 & 6.6 & 19.2 & 25.8 & 21.4 & 1.0 & 105 & 5.1 & 16.7 & 21.8 & 19.3 & 1.0 & 210 & 9.1 & 16.7 & 25.8 & 20.3 & 1.4 \\
\hline OPRT1 & 105 & 7.0 & 23.0 & 30.0 & 25.3 & 1.1 & 105 & 5.2 & 20.5 & 25.7 & 23.1 & 1.0 & 210 & 9.5 & 20.5 & 30.0 & 24.2 & 1.5 \\
\hline OPRT2 & 105 & 7.1 & 22.9 & 30.0 & 25.1 & 1.1 & 105 & 5.7 & 19.9 & 25.6 & 22.7 & 1.1 & 210 & 10.1 & \begin{tabular}{|l|}
19.9 \\
\end{tabular} & 30.0 & 23.9 & 1.6 \\
\hline OPRT3 & 105 & 7.5 & 21.9 & 29.4 & 24.3 & 1.1 & 105 & 5.4 & 19.3 & 24.7 & 21.9 & 1.1 & 210 & 10.1 & \begin{tabular}{|l|}
19.3 \\
\end{tabular} & 29.4 & 23.1 & 1.6 \\
\hline OPRT4 & 105 & 7.5 & 20.6 & 28.1 & 23.0 & 1.0 & 105 & 4.9 & 18.4 & 23.3 & 20.8 & 1.0 & 210 & 9.7 & 18.4 & 28.1 & 21.9 & 1.5 \\
\hline OPRT5 & 105 & 6.3 & 19.2 & 25.5 & 21.3 & 1.0 & 105 & 4.5 & 17.0 & 21.5 & 19.2 & 0.9 & 210 & 8.5 & 17.0 & 25.5 & 20.3 & 1.4 \\
\hline
\end{tabular}


Min: minimum; Max: maximum; OPLT1 to OPLT5: left lengths from anterior part of toes outlines LT1LT5 to outline mid-rear outline heel point OP; OPRT1 to OPRT5: right lengths from anterior part of toes outline RT1-RT5 to mid-rear outline heel point OP; RD: range difference; SD: standard deviation; $\mathrm{N}$ : number of samples.

Table 3 presents means, standard deviations, T-value and P-value of one-sample t-test of bilateral differences (left-right) in foot outline length measurements among males and females In foot outlines, bilateral asymmetry is found at T-3 in males and no significant asymmetry is observed in other toes.

Table 3: One-sample t-test of bilateral differences (left-right) in foot outline length measurements among males and females in adult Melanau ethnics in East Malaysia.

\begin{tabular}{|c|c|c|c|c|c|c|c|c|}
\hline \multirow{2}{*}{ Variables } & \multicolumn{4}{|c|}{ Male (N = 105) } & \multicolumn{5}{c|}{ Female (N = 105) } \\
\cline { 2 - 10 } & $\begin{array}{c}\text { Mean } \\
\text { difference } \\
\text { (left-right) }\end{array}$ & SD & t-Value & P-Value & $\begin{array}{c}\text { Mean } \\
\text { difference } \\
\text { (left-right) }\end{array}$ & SD & t-Value & P-Value \\
\hline $\begin{array}{c}\text { T-1 } \\
\text { (OPLT1-OPRT1) }\end{array}$ & -0.0352 & 0.36 & -1.00 & 0.321 & -0.0876 & 0.33 & -2.68 & $0.009^{*}$ \\
\hline $\begin{array}{c}\text { T-2 } \\
\text { (OPLT2-ORT2) }\end{array}$ & 0.0705 & 0.36 & 2.03 & 0.045 & -0.0114 & 0.34 & -0.34 & 0.731 \\
\hline $\begin{array}{c}\text { T-3 } \\
\text { (OPLT3-OPRT3) }\end{array}$ & 0.1076 & 0.31 & 3.57 & $0.001^{*}$ & 0.0371 & 0.34 & 1.11 & 0.268 \\
\hline $\begin{array}{c}\text { T-4 } \\
\text { (OPLT4-OPRT4) }\end{array}$ & 0.0848 & 0.31 & 2.80 & $0.006^{*}$ & 0.0171 & 0.31 & 0.56 & 0.577 \\
\hline $\begin{array}{c}\text { T-5 } \\
\text { (OPLT5-OPRT5) }\end{array}$ & 0.0857 & 0.30 & 2.94 & $0.004^{*}$ & 0.0714 & 0.32 & 2.28 & $0.024 *$ \\
\hline
\end{tabular}

OPLT1 to OPLT5: left lengths from anterior part of toes outlines LT1-LT5 to outline mid-rear outline heel point OP; OPRT1 to OPRT5: right lengths from anterior part of toes outline RT1-RT5 to outline mid-real outline heel point OP; SD:standard deviation. * ${ }^{*}$-value $<0.05$ is significant.

Table 4: Linear regression equations for stature estimation (in centimeters) from different foot outline length measurements on left and right sides among adult male Melanau ethnics in East Malaysia (N= 105).

\begin{tabular}{|c|c|c|c|c|c|c|c|}
\hline Variables & Regression Equations & SEE & $\mathrm{R}$ & $\mathrm{R}$ & Adj, $\mathrm{R}^{2}$ & $\begin{array}{l}\text { Coefficient } \\
\text { of }\end{array}$ & AN-test \\
\hline OPLT1 & $65.656+3.956$ OPLT1 & 3.576 & 0.780 & 0.608 & 0.604 & 12.635 & $159.645(1,103) ; P<0.001$ \\
\hline OPLT2 & $69.155+3.831$ OPLT2 & 3.730 & 0.757 & 0.573 & 0.569 & 11.765 & $138.420(1,103) ; P<0.001$ \\
\hline OPLT3 & $70.887+3.888$ OPLT3 & 3.806 & 0.746 & 0.556 & 0.551 & 11.352 & $128.862(1,103) ; P<0.001$ \\
\hline OPLT4 & $69.664+4.161$ OPLT4 & 3.823 & 0.743 & 0.552 & 0.547 & 11.258 & $126.735(1,103) ; P<0.001$ \\
\hline OPLT5 & $74.457+4.264$ OPLT5 & 3.914 & 0.728 & 0.530 & 0.526 & 10.782 & $116.261(1,103) ; P<0.001$ \\
\hline OPRT1 & $64.754+3.986$ OPRT1 & 3.812 & 0.745 & 0.554 & 0.550 & 11.320 & $128.135(1,103) ; P<0.001$ \\
\hline OPRT2 & $66.680+3.941$ OPRT2 & 3.886 & 0.733 & 0.537 & 0.532 & 10.926 & $119.374(1,103) ; P<0.001$ \\
\hline OPRT3 & $70.861+3.906$ OPRT3 & 3.910 & 0.729 & 0.531 & 0.527 & 10.803 & $116.705(1,103) ; P<0.001$ \\
\hline OPRT4 & $72.344+4.060$ OPRT4 & 3.874 & 0.735 & 0.540 & 0.535 & 10.990 & $120.785(1,103) ; P<0.001$ \\
\hline OPRT5 & $75.885+4.214$ OPRT5 & 3.924 & 0.727 & 0.528 & 0.523 & 10.730 & $115.130(1,103) ; P<0.001$ \\
\hline
\end{tabular}

OPLT1 to OPLT5: left lengths from anterior part of toes outline LT1- LT5 to outline mid-rear heel point OP; OPRT1 to OPRT5: right lengths from anterior part of toes outline RT1-RT5 to outline mid-rear heel point OP; SEE: standard error of estimate; $\mathrm{R}^{2}$ : coefficient of determination ; Adj, $R^{2}:$ Adjusted $R^{2}$. p-value $<0.001$ is significant. 
Table 5:Linear regression equations for stature estimation(in centimeters) from different foot outline length measurements on left and right sides among adult female Melanau ethnics in East Malaysia $(N=105)$.

\begin{tabular}{|l|l|l|l|l|l|l|c|}
\hline Variables & Regression Equations & $\mathrm{SEE}$ & $\mathrm{R}$ & $\mathrm{R}^{2}$ & Adj, $\mathrm{R}^{2}$ & $\begin{array}{c}\text { Coefficien } \\
\text { t of t-test }\end{array}$ & ANOVA \\
\hline OPLT1 & $42.873+4.802$ OPLT1 & 3.195 & 0.844 & 0.712 & 0.709 & 15.955 & $254.575(1,103) ; P<0.001$ \\
\hline OPLT2 & $54.488+4.346$ OPLT2 & 3.389 & 0.822 & 0.676 & 0.673 & 14.651 & $214.644(1,103) ; P<0.001$ \\
\hline OPLT3 & $57.188+4.375$ OPLT3 & 3.540 & 0.804 & 0.646 & 0.643 & 13.721 & $188.277(1,103) ; P<0.001$ \\
\hline OPLT4 & $55.557+4.692$ OPLT4 & 3.420 & 0.818 & 0.670 & 0.667 & 14.456 & $208.974(1,103) ; P<0.001$ \\
\hline OPLT5 & $59.749+4.854$ OPLT5 & 3.697 & 0.784 & 0.614 & 0.611 & 12.808 & $164.046(1,103) ; P<0.001$ \\
\hline OPRT1 & $41.916+4.826$ OPRT1 & 3.304 & 0.832 & 0.692 & 0.689 & 15.206 & $231.224(1,103) ; P<0.001$ \\
\hline OPRT2 & $53.807+4.374$ OPRT2 & 3.551 & 0.803 & 0.644 & 0.641 & 13.654 & $186.422(1,103) ; P<0.001$ \\
\hline OPRT3 & $53.809+4.536$ OPRT3 & 3.530 & 0.805 & 0.648 & 0.645 & 13.781 & $189.928(1,103) ; P<0.001$ \\
\hline OPRT4 & $54.815+4.732$ OPRT4 & 3.478 & 0.812 & 0.659 & 0.655 & 14.095 & $198.681(1,103) ; P<0.001$ \\
\hline OPRT5 & $58.766+4.924$ OPRT5 & 3.824 & 0.766 & 0.587 & 0.583 & 12.106 & $146.565(1,103) ; P<0.001$ \\
\hline
\end{tabular}

OPLT1 to OPLT5: left lengths from anterior part of toes outline LT1- LT5 to outline mid-rear heel point OP; OPRT1 to OPRT5: right lengths from anterior part of toes outline RT1-RT5 to outline mid-rear heel point OP; SEE: standard error of estimate; $\mathrm{R}^{2}$ : coefficient of determination ; $\mathrm{Adj}, R^{2}$ : Adjusted $R^{2}$.

p-value $<0.001$ is significant

Table 6: Linear regression equations for stature estimation (in centimeters)from different foot outline length measurements on left and right sides among pooled samples of adult Melanau ethnics in East Malaysia $(N=210)$.

\begin{tabular}{|l|l|c|c|c|c|c|c|}
\hline Variables & Regression Equations & SEE & $R$ & $R^{2}$ & $\begin{array}{c}\text { Adj, } R \\
2\end{array}$ & $\begin{array}{c}\text { Coefficient } \\
\text { of t-test }\end{array}$ & ANOVA \\
\hline OPLT1 & $40.922+4.912$ OPLT1 & 3.506 & 0.911 & 0.830 & 0.829 & 31.880 & $1016.317(1,208) ; P<0.001$ \\
\hline OPLT2 & $49.083+4.607$ OPLT2 & 3.644 & 0.904 & $\begin{array}{c}0.816 \\
*\end{array}$ & $\begin{array}{c}0.816 \\
*\end{array}$ & 30.420 & $925.403(1,208) ; P<0.001$ \\
\hline OPLT3 & $50.867+4.687$ OPLT3 & 3.756 & 0.897 & 0.805 & 0.804 & 29.304 & $858.698(1,208) ; P<0.001$ \\
\hline OPLT4 & $49.156+5.026$ OPLT4 & 3.712 & 0.900 & 0.810 & 0.809 & 29.735 & $884.153(1,208) ; P<0.001$ \\
\hline OPLT5 & $52.503+5.262$ OPLT2 & 3.909 & 0.888 & 0.789 & 0.788 & 27.879 & $777.257(1,208) ; P<0.001$ \\
\hline OPRT1 & $38.327+5.007$ OPRT1 & 3.683 & 0.901 & 0.813 & 0.812 & 30.032 & $901.903(1,208) ; P<0.001$ \\
\hline OPRT2 & $45.985+4.742$ OPRT2 & 3.804 & 0.894 & 0.800 & 0.799 & 28.845 & $832.054(1,208) ; P<0.001$ \\
\hline OPRT3 & $48.309+4.812$ OPRT3 & 3.816 & 0.894 & 0.799 & 0.798 & 28.736 & $825.776(1,208) ; P<0.001$ \\
\hline OPRT4 & $48.159+5.083$ OPRT4 & 3.805 & 0.894 & 0.800 & 0.799 & 28.840 & $831.741(1,208) ; P<0.001$ \\
\hline OPRT5 & $52.464+5.285$ OPRT5 & 3.983 & 0.884 & 0.781 & 0.780 & 27.213 & $740.568(1,208) ; P<0.001$ \\
\hline
\end{tabular}

OPLT1 to OPLT5: left lengths from anterior part of toes outline LT1- LT5 to outline mid-rear heel point OP; OPRT1 to OPRT5: right lengths from anterior part of toes outline RT1-RT5 to outline mid-rear heel point OP; SEE: standard error of estimate; $\mathrm{R}^{2}$ : coefficient of determination ; $\operatorname{Adj}, R^{2}$ : Adjusted $R^{2}$. p-value $<0.001$ is significant

Tables - 4 to 6 show the linear regression equations for stature estimation in adult males, females and pooled sample through various foot out line lengths with ANOVA. The standard error of estimate (SEE) in case of female foot outline length (3.195-3.824) is comparatively lower than that of males (3.576-3.914) and pooled sample (3.506-3.983). The correlation coefficient $(\mathrm{R})$ between stature and various foot outline lengths is statistically significant $(<0.001)$. $\mathrm{R}$ values are found to be more in the pooled sample (0.884-0.911) when compared with males $((0.727-0.780)$ and females $(0.766-$ $0.844)$. The coefficient of determination $\left(R^{2}\right)$, the predictive accuracy, is found to be higher in the pooled sample (0.781-0.830) when compared with males (0.528-0.608) and females (0.587-0.712) and all measurements are 
found to be positive and statistically significant for stature estimation.

\section{DISCUSSION}

It is common to find the 2D footprints at indoor crime scenes while foot outline drawn from 3D footprint at outdoor crime scenes mostly left by perpetrators ${ }^{22}$. The foot outline can be scientifically analyzed to establish the biological profile and confirm an association of an accused with the crime scene. The present investigation shows that stature and foot outline size are found to be larger in males than females, showing the existence of a statistically significant sex difference. This may be attributed to general male-female differences and natural size in both sexes ${ }^{26}$. This finding is concordant with previous research findings $4,10,17,21,22$. The size of male left foot outline is found to be slightly larger in $\mathrm{T}-3$ than the right side but in female the bilateral asymmetry i.e. left-sided asymmetry is not significant. The significant bilateral asymmetry were observed by other researchers in Egyptian ${ }^{\mathbf{1 4}}$, Malaysian Malays ${ }^{17}$, north Indian male Gujjars ${ }^{20}$, Malaysian Chinese ${ }^{21}$, Ibans of East Malaysia ${ }^{22}$ and Indian population ${ }^{26}$. Philip did not find significant bilateral asymmetry while working on the footprints of south Indian population ${ }^{2}$. Similarly Ilayperuma ${ }^{5}$ and Robbins ${ }^{27}$ also did not find significant bilateral asymmetry in various measurements of the feet of the Sri Lanka and U.S. population. Researchers indicated that regression equations can be derived for stature estimation using foot and hand measurements with a great accuracy and a small SEE, i.e. about $2-6 \mathrm{~cm}^{28}$. The age range of the subjects in this investigation is considered appropriate since the average length of adult's foot is attained at 16 years in male and 14 years in females ${ }^{29,30}$. Commonly, stature at 18 years is accepted as adult, although there are small increments in stature after this ${ }^{31,32}$. It is interesting to note that the correlation coefficient $(\mathrm{R})$ between stature and foot outline measurements regardless of sex, i.e. when male and female subjects are pooled together, gave a more significant result than the correlations separately obtained for the males and females. The scatter graphs obtained by plotting various foot outline lengths and height in the pooled sample visually (Figure 3) confirm the strong positive correlation between height and foot outline length measurements. This finding is consistent with previous studies of Malays ${ }^{4}$ Malaysian Chinese ${ }^{21}$ and Indians ${ }^{26}$. Considering real crime scenarios, where the sex of the perpetrator is unknown, it is suggested that a better regression equation that can be used for stature estimation is the one without sex indicators.
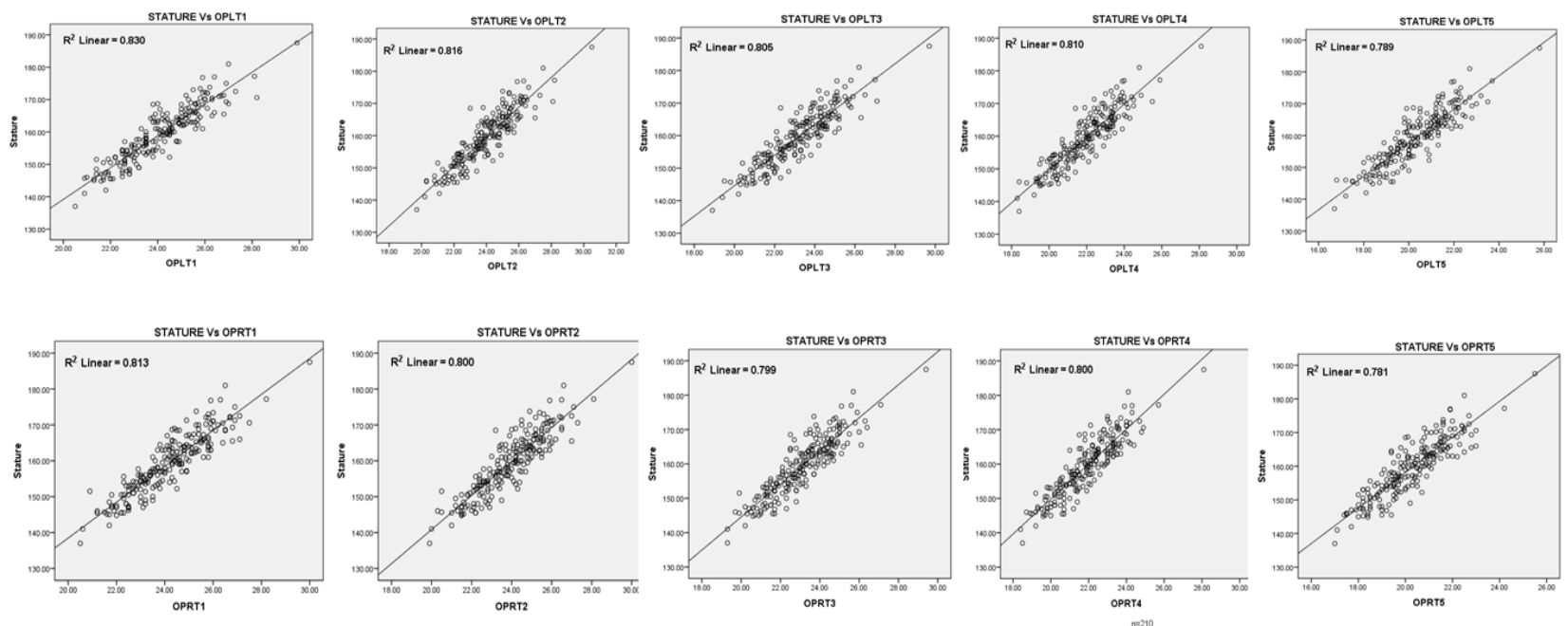

Figure 3: Illustrative example of scatter graphs showing the relationship between various foot outline lengths and stature in pooled sample of Malanau ethnics in east Malaysia $(N=210)$. 


\section{CONCLUSION}

The result of this investigation provided regression equations for stature estimation from foot outline (complete or partial) measurements in Melanaus of East Malaysia in northern Borneo Island. The regression equation derived for the pooled sample can be employed to estimate stature when the sex of the perpetrator remains unknown, as in real crime scenarios. It is important to note that the people from different races and regions of Malaysia bear different morphological features depending upon their geographical distribution and primary racial characteristics and a single formula cannot represent all parts of the country. It would be incorrect to utilize the equations to estimate stature from foot outline measurements derived for Melanaus to any other populations either in Malaysia or any other populations in the world. Hence it is suggested that similar studies should be continued on other ethnic groups living in different parts of the world so that effect of genetic and environment can be investigated in forensic terms.

\section{CONFLICT OF INTEREST}

The authors have no conflict of interest to declare.

\section{ACKNOWLEDGMENT}

The authors are thankful to all participants who took part in this strenuous study. Thanks are due to Sarawak state Chief Minister, Sarawak state Police Chief, Forensic Police Investigating Officers and Chemistry Department of Malaysia, Bintulu Branch, East Malaysia for their support to conduct this research. Authors are grateful to Universiti Sains Malaysia for encouraging research and its publication in international journals.

\section{REFERENCES}

1. Jahar JK, Vijay P, Paliwal PK. Estimation of height from measurements of foot length in Haryana region. Journal of Indian Academy of Forensic Medicine 2010; 32:231-233.

2. Philip TA. Formulae for establishing stature from foot size by regression method. Journal of Indian Academy of Forensic Medicine 1990;12:57-62.

3. Krishan K. Individualizing characteristics of footprints in Gujjars of north India-forensic aspects. Forensic Science International 2007;169:137-144.

4. Nataraja Moorthy T, Mazidah K, Hadzri M, Jayaprakash PT. Estimation of stature based on foot length of Malays in Malaysia. Australian Journal of Forensic Sciences 2011;43:13-26.

5. Ilayperuma I , Nanayakkara BG, Palahepitiya KN. A model for reconstruction of personal stature based on the measurements of foot length. Galle Medical Journal 2008;13(1): 6-9

6. Petra U, Radoslav B, Sona M. Stature estimation from various foot dimensions among Slovak population. Journal of Forensic Sciences 2013; 58(2): 448-451.

7. Mansur DI, Haque MK,Sharma K, Karki RK, Khanal K,Karna R. Estimation of Stature from Foot Length in Adult Nepalese Population and its Clinical Relevance. Kathmandu University Medical Journal 2012; 37(1):16-9.

8. Ogugua E, Nto NJ, Bello EF, Egwu EO, Ukoha UU, Ajah D. Stature Estimation from Foot Dimensions of an Adult Nigerian Population. Anatomica Karnataka 2012; 6(2):08-12.

9. Sonali K,Ashias A. Estimation of stature from the measurement of foot length, hand length and head length in Maharashtra region. Indian Journal of Basic \& Applied Medical Research 2012; 1(2): 77-85.

10. Salina H, Mamat S, Che R, Ibrahim, Mohamad A. Regression analysis for stature estimation from foot anthropometry inMalaysian Chinese. Australian Journal of Forensic Sciences 2012; 44 (4): 333-341.

11. Pradeep KP, Abhilasha D. Study of correlation between human height and foot length in residents of Mumbai. International Journal of Biological and Medical Research 2012; 3(3): 2072 -2075.

12. Robbins LM. Estimating height and weight from size of footprints. Journal of Forensic Sciences 1986; 31:143-52.

13. Kennedy RB, Chen S, Pressman IS, Yamashita AB, Pressman AE. A large scale statistical analysis of bare foot impressions. Journal of Forensic Sciences 2005;50:1071-1080

14. Irene Atef Fawzy,1 M.D. and Nashwa Nabil Kamal,2 M.D. Stature and Body Weight Estimation from Various Footprint Measurements Among Egyptian Population. Journal of Forensic Sciences 2010; 55(4): 884-888 
15. Reel S, Rouse S, Vernon W, Doherty D. Estimation of stature from static and dynamic footprints. Forensic Science International 2012; 219: 283.e1-283.e5.

16. Naomi H, Ambika F, Nur-Intaniah I, Daniel F, Tytuł A. Estimation of stature using anthropometry of feet and footprints in a Western Australian population. Journal of Forensic and Legal Medicine 2013; 20(5): 435-441.

17. Nataraja Moorthy T, Nurul A, Hairun Nisa M. Stature estimation based on footprint measurements of Malays in Peninsula Malaysia by regression analysis. International Journal of Biomedical and Advance Research 2013; 4(10):683-689.

18. Nataraja Moorthy T, Mustaqqim A, Boominathan R, Raman N. Stature estimation from footprint measurements in Indian Tamils by regression analysis. Egyptian J Forensic Sci 2013; In press, Available online 5 December 2013.

19. Robbins LM. The individuality of human footprints. Journal of forensic sciences 1978; 23(4): 778-785.

20. Krishan K. Estimation of stature from footprint and foot outline dimensions in Gujjars of North India. Forensic Science International 2008; 175: 93-101.

21. Nataraja Moorthy T, Ang YL, Saufee AS. Estimation of stature from footprint and foot outline measurements in Malaysian Chinese, Australian Journal of Forensic Sciences 2013; Doi.org/10.1080/00450618.2013.825813: e1-e24 .

22. Hairunnisa MAK, Nataraja Moorthy T. Estimation of stature from foot outline measurements in Ibans of East Malaysia by regression analysis. International Journal of Biomedical And Advance Research 2013; 04 (12): 1-7.

23. Whitehouse RH, Tanner JM, Healy MJ. Diurnal variation in stature and sitting height in 12-14year-old boys. Annals of Human Biology 1974; 1:103-6.
24. Krishan K, Vij K. Diurnal variation of stature in three adults and one child. Anthropologist 2007; 9:113-117.

25. Krishan K, Kanchan T, Sharma A. Multiplication factor versus regression analysis in stature estimation from hand and foot dimensions. Journal of Forensic and Legal Medicine 2012; 19:211214.

26. Kanchan T, Krishan K, Shyamsundar S, Aparna $\mathrm{KR}$, Jaiswal S, Analysis of footprint and its parts for stature estimation in Indian population. The Foot 2012; 22 ( 3): 175-180.

27. Robbins LM. Footprints-collection, analysis and interpretation, Charles C, Thomas, Spring Field, IL, USA, 1985.

28. Krishan K, Abihilasha S. Estimation of stature from dimension of hand, feet in north Indian population. Journal of Forensic and Legal Medicine 2007;14:327-332.

29. Anderson M, Bias M, Green WT. Growth of the normal foot during childhood and adolescencelength of the foot and interrelations of foot, stature and lower extremity as seen in serial records of children between 1-18 years of age. American Journal of Physical Anthropology 1956;14:287308.

30. Blais MM, Green WT, Anderson M. Lengths of the growing foot. Journal of Bone and Joint Surgery 1956;38:998-1000.

31. Roche AF, Davila GH. Late adolescent growth in stature. Pediatrics 1972;50:874-880.

32. Nagesh Kumar G, Kotian MS. Footprint ratio (FPR) - a clue for establishing sex identity. Journal of Indian Academy of Forensic Medicine 1990;12:51-56. 